\title{
USO E OCUPAÇÃO DO SOLO ENTRE TRANCOSO E ARRAIAL D'AJUDA, COSTA DO DESCOBRIMENTO, LITORAL SUL DO ESTADO DA BAHIA Diego Oliveira Silva ${ }^{1}$; Carlos César Uchôa de Lima ${ }^{2}$ \\ 1. Bolsista PIBIC/CNPq, Graduando em Engenharia Civil, Universidade Estadual de Feira de Santana, e-mail: ogeid.oliveira1@gmail.com \\ 2. Orientador, Departamento de Ciências Exatas, Universidade Estadual de Feira de Santana, e-mail: uchoamaster@gmail.com
}

PALAVRAS-CHAVE: Usos e Ocupação; Urbanização; Vegetação.

\section{INTRODUÇÃOO}

Os estudos sobre o uso e ocupação do solo além de compreenderem uma análise temporal, espacial e antrópica de um território, dão embasamento aos órgãos gestores locais para um gerenciamento consciente e responsável das características locais. Todavia esse tema é abordado de forma concentrada nas áreas continentais. Ao passo que as regiões costeiras dispõem de pouca atenção nas pesquisas já realizadas.

A região conhecida como Costa do Descobrimento, localizada ao extremo sul da Bahia, compreende o conjunto de municípios localizados entre Belmonte e Prado, abrangendo uma área de 7.552,5 km² (GALLO NETO, 2011, p.4). Dotada de muitas belezas naturais como praias, manguezais, falésias, rios e fauna diversa, esta costa segue como alvo de turistas e empreendedores.

Como afirma Reis Amorim (2013, p.213), até cerca de 1970, os municípios que integram a região Costa do Descobrimento integravam economicamente a Região Cacaueira que, até o final da década de 1980. Porém, com a crise da monocultura cacaueira e a chegada das Comemorações do V Centenário do Descobrimento do Brasil se fez necessária a implantação de novas bases econômicas, como a industrialização de bens de consumo duráveis e não duráveis e a implantação da atividade turística (explorando os potenciais naturais e culturais) (REIS, 2013, p.213).

A presente pesquisa foca na análise do processo de uso e ocupação numa porção desta costa localizada no Município de Porto Seguro: entre Arraial d'Ajuda e Trancoso. Objetivando a investigação da ação humana, através das intervenções da construção civil como modificadora de tal cenário em dois aspectos principais: expansão urbana e modificação de áreas vegetadas próximas à faixa litorânea.

\section{METODOLOGIA}

A metodologia utilizada foi a análise de imagens do banco de dados do satélite Landsat através do Google Earth Engine. Para todas as imagens houve a sobreposição do mapa que denota as áreas de expansão através de cores e uma imagem do mapa original do Google Earth Engine para referenciar cada intensidade de modificação local.

Relativo à urbanização foram utilizadas imagens entre 2000 e 2014 obtidas pelo Landsat 8. Nas duas foram aplicadas as bandas B3, B2 e B1 para ressaltar a urbanização. Através da comparação entre as mesmas, obteve-se a imagem que determina modificação entre as duas por cores. Dentre as zonas observadas, para melhor organizar a detecção, a faixa estudada foi subdividida em duas zonas próximas às sedes distritais buscando as regiões de maior concentração de regiões amarelas e vermelhas (Figuras 1 e 2).

Referente à vegetação a imagem do ano de 2017 foi retirada do Landsat 8 e a de 1987 do Landsat 5. Nas duas foram utilizadas as bandas B3, B4 e B5 para ressaltar a vegetação. Além disso, utilizou-se o conceito de Índice de Vegetação por Diferença Normalizada (NDVI) com a expressão NDVI=(B4-B3)/(B4+B3). Essa análise foi executada descrevendo as regiões de maior modificação da vegetação no período abordado (Figura 3). 
Foi utilizado a ferramenta área do Autocad $2 \mathrm{~d}$ para encontrar áreas aproximadas relativas às expansões de média e intensa modificação urbana e vegetal.

\section{RESULTADOS E/OU DISCUSSÃO}

A área 1 corresponde às imediações do distrito de Arraial d'Ajuda como demonstra a Figura 1. Nessa região observou-se a alteração urbana em 2 subáreas de extensão considerável: litorânea e continental.

$\mathrm{Na}$ parte litorânea a modificação urbana foi classificada como média, evidenciada pela frequência da cor amarela neste local no mapa da Figura 1. Analisando imagens do Street View Google Maps de 2014 nesta subárea foi notada a existência de hotéis, pousadas, restaurantes, bares e villages em meio a casas em sua maioria de veraneio (caracterizadas assim pelas placas de aluga-se) e lotes ainda não construídos.
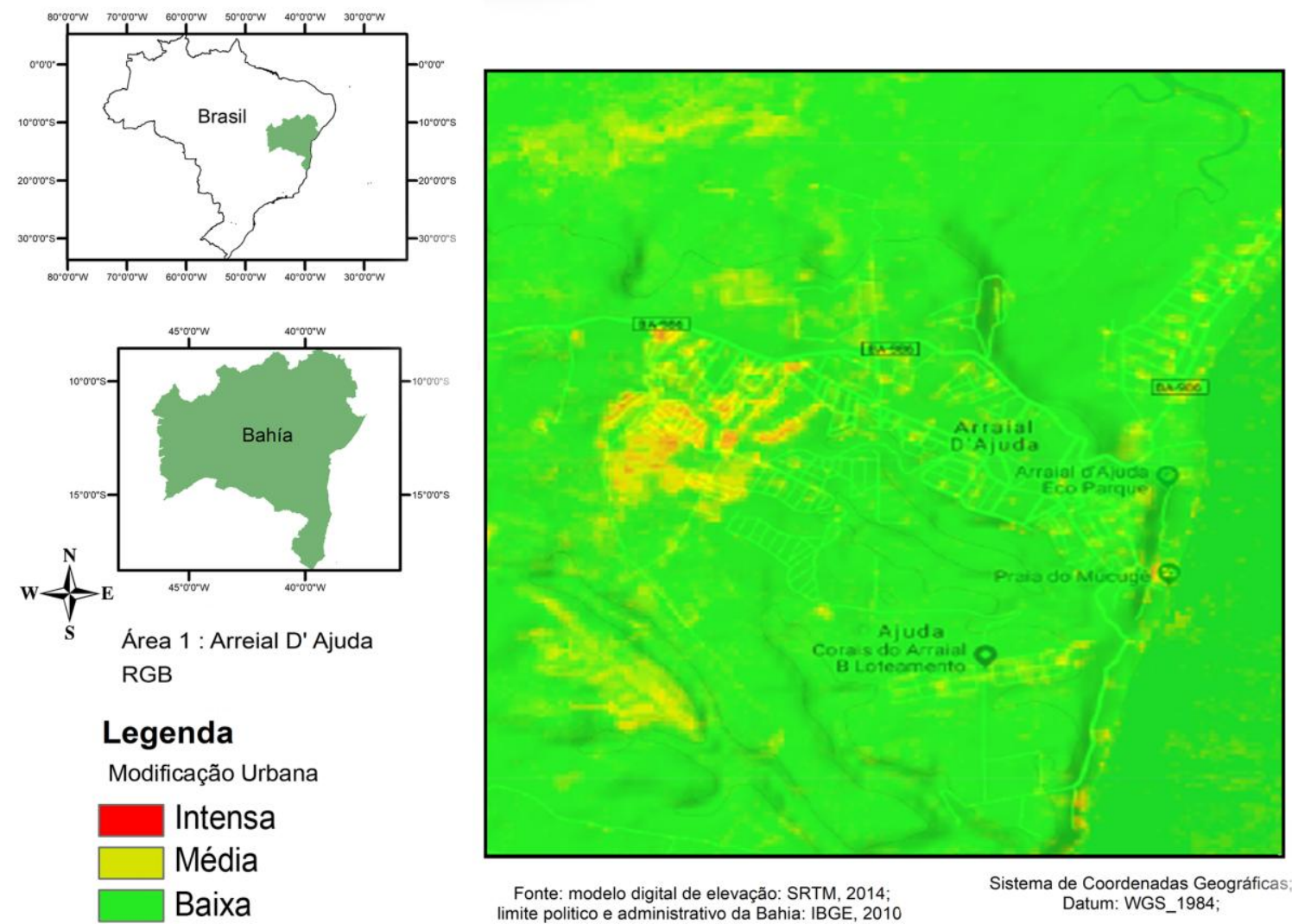

Figura 1: Mapa de Alteração Urbana referente à Área 1 - Arraial d'Ajuda

A subárea continental se localiza a oeste da Igreja Matriz Nossa Senhora d'Ajuda. Nela foi percebida a presença não só de regiões amarelas como vermelhas, característica de média e intensa alteração urbana respectivamente (Figura 2). Nessa região foi possível notar a presença de novas zonas urbanas assim como de solo exposto indicando desmatamento. Em sua maioria, as habitações de Arraial d'Ajuda seguem um padrão construtivo em alvenaria e detalhamento em madeira, como fachadas e esquadrias.

A área 2 é mais centrada na região de Trancoso. Nessa área, houve o maior número de zonas de média e intensa alteração urbana no período estudado entre as áreas 1 e 2, expressas respectivamente pelas cores amarelo e vermelho concentradas a leste do Quadrado de Trancoso (Figura 2). As alterações na urbanização foram visualizadas em blocos de expansão, enumerados de 1 a 4 na Figura 2, ao longo da BA-987 em direção à Estrada de Trancoso. Sendo assim, esta via se tornou um vetor de desenvolvimento socioeconômico no distrito de Trancoso. 

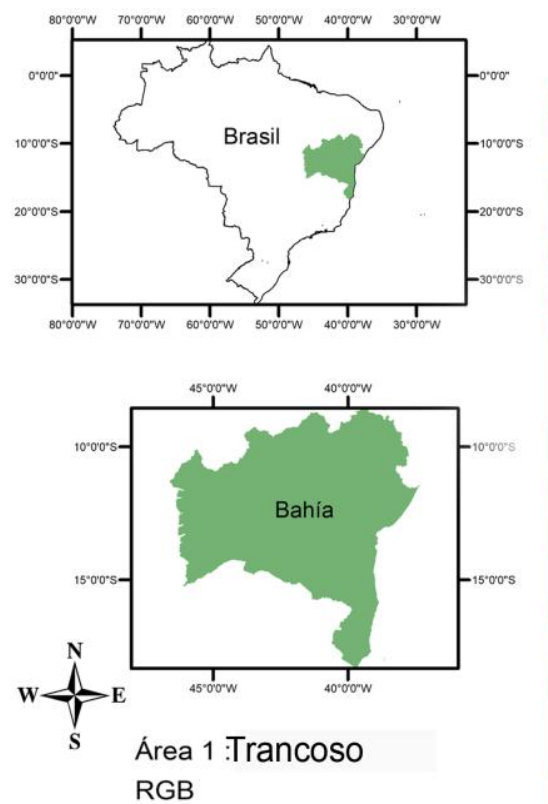

\section{Legenda}

Modificação Urbana

Intensa

Média

Baixa

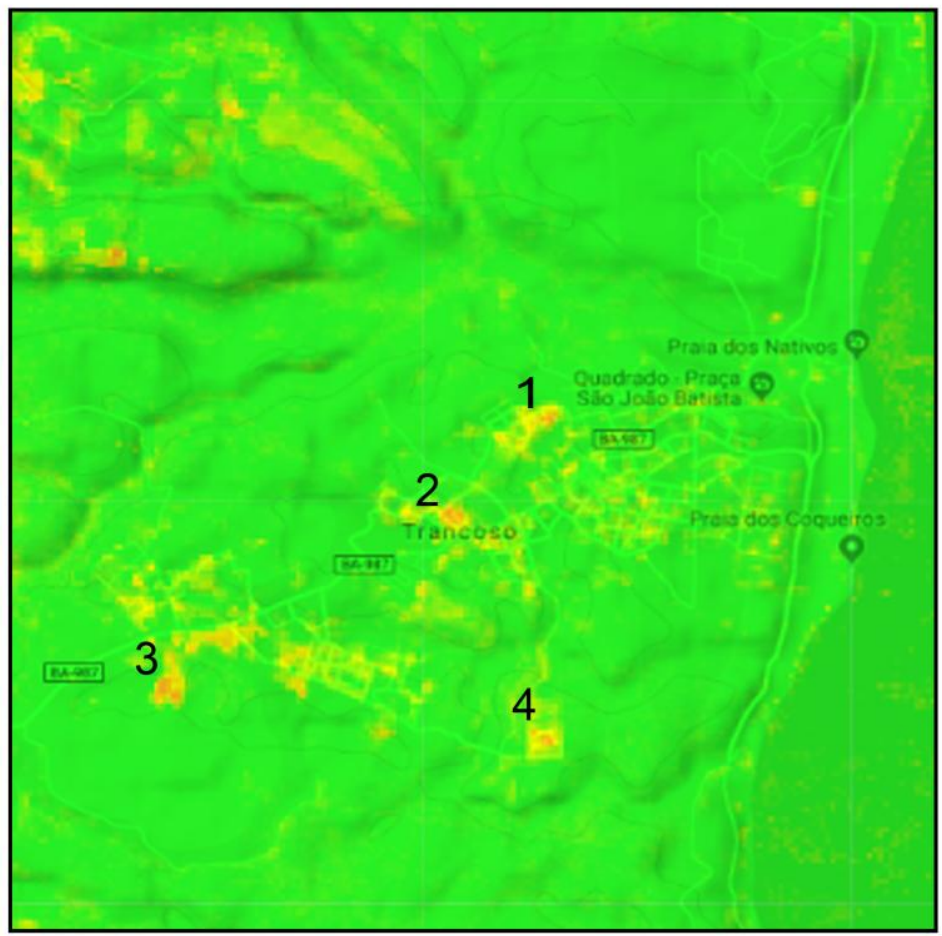

Sistema de Coordenadas Geográficas; Datum: WGS_1984;

Fonte: modelo digital de elevação: SRTM, 2014; limite politico e administrativo da Bahia: IBGE, 2010

Figura 2: Mapa de Alteração Urbana referente à Área 2 - Trancoso

Analisando as alterações da vegetação, foi possível entender a diferenciação dos espaços de uma forma mais abrangente quando adentrou-se o continente uma vez que o litoral apresentou modificações mais concentradas nos centros urbanos, cor laranja, com predominância de baixa ou inexistente alteração no restante dessa faixa, cor verde clara (Figura 3).

Num enfoque da área continental foram notadas regiões de modificação concentrada. Tomando como referência a BA-001 no sentido leste-oeste foi possível identificar uma grande quantidade de zonas laranja indicando média intensidade de mudança na vegetação. Essa característica inicia sua intensificação em duas direções: a primeira é a cerca de 2,0 km a noroeste de Trancoso, próximo ao Parque Nacional do Pau Brasil, e a segundo segue o curso do Rio dos Frades. 

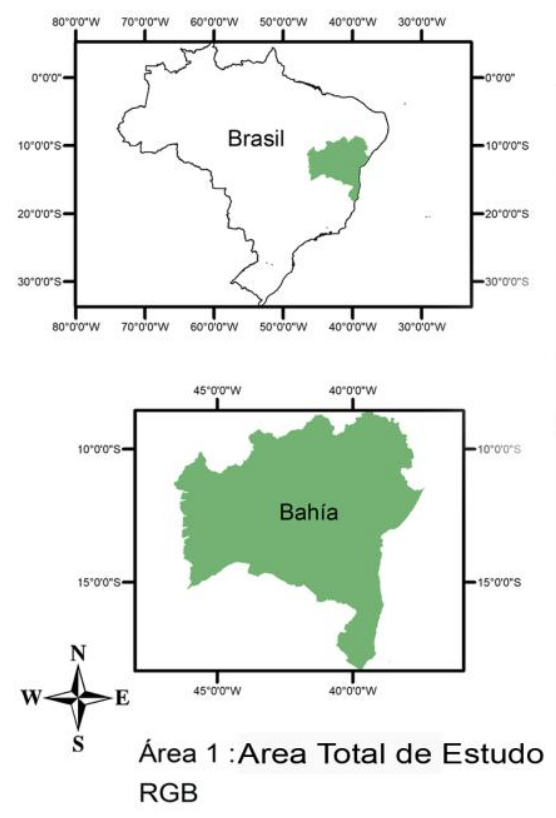

\section{Legenda}

Modificação Vegetal

Intensa

Média

Baixa

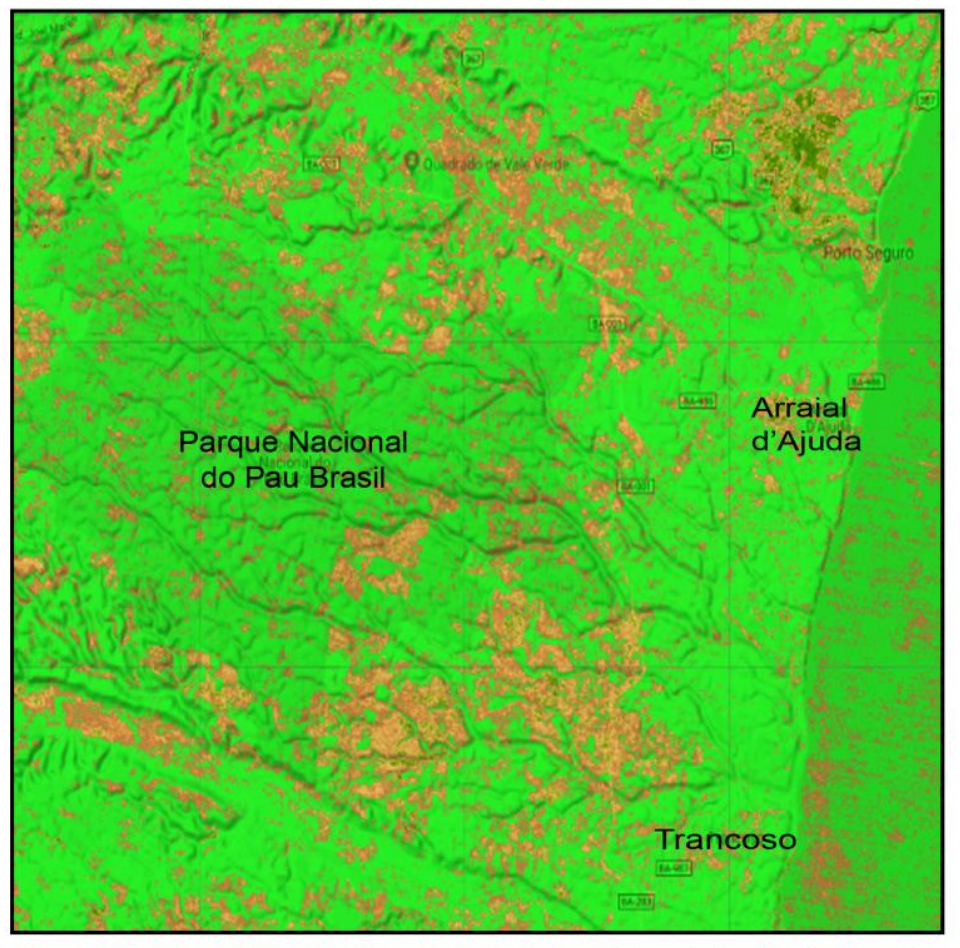

Sistema de Coordenadas Geográficas:

Fonte: modelo digital de elevação: SRTM, 2014 limite politico e administrativo da Bahia: IBGE, 2010

Datum: WGS_1984;

Figura 3: Mapa de Alteração Vegetal referente à Área de Estudo

\section{CONSIDERAÇÕES FINAIS (ou Conclusão)}

Através desta pesquisa foi possível identificar, entre Arraial d'Ajuda e Trancoso, a existência de áreas de expansão urbana consideráveis nas proximidades das sedes distritais. Para os distritos de Arraial d'Ajuda e Trancoso, houve respectivamente um total de 720.000,00 m² e 367.000,00 m² de suas áreas com média e intensa alteração.

Foram notadas também transformações consideráveis na vegetação nos dois distritos estudados, das quais a região de Trancoso se destaca em média intensidade de alteração vegetal quando observada em direção ao interior. Em Arraial d'Ajuda a área de modificação intensa e média da vegetação, no período estudado, foi de 13.000.000,00 $\mathrm{m}^{2}$ enquanto que em Trancoso, alcançou 18.000.000,00 $\mathrm{m}^{2}$. Dentre as zonas de mudança do espaço vegetado a que mais chama atenção é a faixa próxima ao Parque Nacional do Pau Brasil devido à utilização indevida de solos reservados para a proteção ambiental e patrimonial para fins socioeconômicos.

\section{REFERÊNCIAS}

GALLO NETO, Carmo. Mapeando a Costa do Descobrimento: Cartas cartográficas podem subsidiar ações de gestão e planejamento. Jornal da Unicamp, Campinas, São Paulo, 29 ago. 2011., p. 4. Disponível em: <http://www.unicamp.br/unicamp/unicamp_hoje/ju/agosto2011/ju504pdf/Pag04.pdf>. Acesso em: 20 mar. 2017.

REIS AMORIM, R; de OLIVEIRA, R. Zoneamento ambiental, subsídio ao planejamento no uso e ocupação das terras da costa do descobrimento. Mercator Revista de Geografia da UFC. v. 12. n. 29, p. 211-231. set-dez. 2013. 